High Prevalence of Acute Pancreatitis during the

Ramadan Fast

Rona Zuker Herman ${ }^{1}$, Shahaf Shiber, ${ }^{1}$ Micheal Dresher ${ }^{2}$, Amir Agabaria ${ }^{2}$, Tony Bleetman ${ }^{2}$, Genady Drozdinsky ${ }^{2}$

1. Rabin Medical Center, Petach Tiqva/Israel

2. Rabin Medical Center, Kfar Sirkin/Israel

Study/Objective: Our study tried to identify different patterns of occurrence during the Ramadan fast of Acute Pancreatitis (AP).

Background: Acute Pancreatitis (AP) is an acute inflammatory process of the pancreas. The aim of this is study is to retrospectively screen and record the Muslim and non-Muslim patients, admitted to the emergency department with acute pancreatitis over a ten-year period, in order to identify different pattern of occurrence during the Ramadan fast.

Methods: The study was conducted at the Emergency Department of Rabin Medical Center (Beilinson campus) in Petach Tikva, Israel. We compared the occurrence ratio of AP in Muslim populations and non-Muslim populations during the Ramadan fasting days, versus the rest of the year. We reviewed the medical records of Muslim patients admitted to the emergency department during the Ramadan fast period, to identify those who had reported that they fasted. In order to calculate prevalence of acute pancreatitis, we recorded the overall admissions to the emergency department during the years 2006-2016, of Muslim and non-Muslim patients.

Results: Over the 10-year study period, 1,167 patients were admitted to the emergency department with a diagnosis of acute AP. The number of patients with AP during the Ramadan periods were statistically significance between the non-Muslim and the Muslim groups 95 (8.8\%) patients vs. 17(17.3\%) patients, $\mathrm{p}=0.01$, respectively). The prevalence of AP during the Ramadan periods among Muslim were 11.28 for 10,000 vs. 8.9 for 10,000 for Muslims in other periods vs. 7 per 10,000 for the cohort population in ant period $(\mathrm{p}<0.001)$.

Conclusion: We found a high prevalence rate of acute pancreatitis in the Muslim population during the Ramadan fast. Physicians should be aware of this link and suspect it, for Muslim patients presenting with epigastric pain during the Ramadan fast. The proposed mechanism for the development of pancreatitis is acute gastric dilation.

Prehosp Disaster Med 2017;32(Suppl. 1):s61-s62

doi:10.1017/S1049023X17001686

\section{Patient Safety in Greek Hospitals}

\section{Leonidas Liakopoulos ${ }^{1}$, Helen Pavlidou ${ }^{2}$, Markos Maragkos ${ }^{3}$,}

Dimitrios Velissaris ${ }^{3}$, Georgios Soufras ${ }^{2}$, Charalambos Gogos ${ }^{3}$

1. Health Center K. Achaia, Patras/Greece

2. Emergency Dpt., General Hospital of Patras, Patras/Greece

3. Internal Medicine, Medical School of University of Patras, Patras/ Greece

Study/Objective: This paper aims to investigate the problem of patient safety in Greek hospitals.

Background: Safety issues for hospitalized patients have been a great concern for health care providers over the last 15 years. In developed countries, one in 10 patients experiences the consequences of a medical error during hospitalization. The World Health Organization (WHO) defines patient safety as their protection from preventable injuries that occur during the provision of health care, and at the same time, it sets patient safety as a world priority regarding health issues.

Methods: Greek and international publications in PUBMED during the last 10 years, and data collected by highly certified international organizations (WHO, OECD, HCDCP, JC, and AHRQ), have been extensively reviewed. We also present the results of a small indicative questionnaire on Hand Hygiene. Keywords: "Patient safety;" "Medical error;" and "Greek Hospital."

Results: The majority of Greek citizens believe that health care services provided in the country are inferior compared to countries of the European Union. In most hospitals, there are neither established protocols on the safe management of patients nor integrated reporting systems of the adverse events. Informed consent is inadequate. Prescription of antibiotics is two-fold compared to the average rate in the OECD countries. The shortage of nursing staff worsened after the economic crisis emerged. The average number of nurses per 1,000 residents is 3.6, compared to 9.1 in OECD countries. Burnt out syndrome is reported by $78 \%$ of the nursing staff. The most of medical errors are reported by Surgery and Obstetrics $(20 \%$ and $16 \%$, respectively). On the other hand, there is good monitoring and recording of adverse events in blood transfusions.

Conclusion: It is obvious that we need better education, development of reporting systems, supportive work environment, loyal implementation of internationally recognized practices, and collaboration among the different health care structures.

Prehosp Disaster Med 2017;32(Suppl. 1):s62

doi:10.1017/S1049023X17001698

\section{An Epidemiological Survey Correlating with Survival}

Probability in Cases of Abdominal Trauma in a Rural Setup Anand Thawait, Sankalp Dwivedi

Surgery, Maharishi Markandeshwar Institute of Medical Sciences and Research, Mullana, Mullana/India

Study/Objective: The study was designed to assess epidemiology of abdominal trauma in a rural setup, and correlate it with survival probability of the patient, through revised trauma score.

Background: Trauma is a major public health problem in every country, with abdominal trauma being 3 rd most common. The profile and pattern of abdominal trauma is changing with a progressing civilization. Understanding mechanisms of injury is crucial, while managing a patient with abdominal trauma. An epidemiological assessment of trauma can help to predict mortality and morbidity. Early diagnosis, sound clinical judgement and prompt intervention in abdominal trauma is necessary. Methods: The study comprised of 50 patients of abdominal trauma attending the emergency department, in whom the epidemiological profile of trauma was recorded as 'per prescribed proforma, and later correlated with revised trauma score and survival probability. 
Results: A total of 50 patients (mean age of $32.98 \pm 12.61$ years) were included in the study. Majority (86\%) had blunt abdominal trauma, (14\%) had penetrating injuries and associated polytrauma was seen in 34\%. Majority of patients were brought by personal vehicles (42\%) followed by ambulance only $34 \%$. The mean duration of injury till hospitalization was $17.68 \pm 21.78 \mathrm{hrs}$, with $50 \%$ patients getting hospitalized within 6 hrs. Prehospital Care, by ambulance, police or referring hospitals could only be offered in $68 \%$. The most common cause was road traffic accidents (42\%). Mean GCS and Revised Trauma Score were found to be $13.76 \pm 2.33$ and $7.28 \pm 0.92$. Mean hospital stay was $11.5 \pm 3.64$ days while mortality was $2 \%$. Conclusion: A young productive age group is more vulnerable to abdominal trauma. Considering the fact that road-related accidents are quite predictable and controllable; therefore, the quality promotion of traumatic patients care, and road safety should be strengthened, as the majority still come in late beyond golden hours.

Prehosp Disaster Med 2017;32(Suppl. 1):s62-s63

doi:10.1017/S1049023X17001704

Budgeting of a Local Government for Disaster and Health Crisis in Indonesia

Bella Donna ${ }^{1}$, Mubammad F. Kurniawan ${ }^{2}$, Budi E. Siswoyo ${ }^{2}$, Madelina Ariani ${ }^{1}$, Ina A., Isturini ${ }^{3}$

1. Health Policy And Management, Center for Health Policy and Management, Faculty of Medicine, Universitas Gadjah Mada, Sleman, Yogyakarta/Indonesia

2. Public Health, Center for Health Policy and Management, Faculty of Medicine, Universitas Gadjah Mada, Yogyakarta/Indonesia

3. Health Crisis Center Ministry of Health, Indonesia., Jakarta/ Indonesia

Study/Objective: To describe a disaster and health crisis budget by local government in Indonesia; to see if districts with a higher disaster risk had been developing adequate budgets for preparedness and disaster management.

Background: Adequate financing is one of the main facets of implementing disaster and health crisis management. It is not just a national responsibility, it must be a local responsibility also. In the past 5 years (2009-2013) the 'prone' districts have experienced many disasters and health crisis, and must have a good plan, including a budget for preparedness and disaster management.

Methods: This study used descriptive, with cross sectional design. The subject study was in 6 districts in North Sumatra, South Sulawesi, and Papua Province. Three provinces were representative of Regional Health Crisis of Indonesia for east, central, and west part. Unit analysis of this study was budget allocation from a program planning and budgeting document of the health district office 2012-2013.

Results: There was no budget for disaster in the Health District Office (HDO), because it was allocated in Local Emergency and Management Authority (LEMA). Whereas, many health issues are impacted due to a disaster event. Commonly, they just budgeted for preparing and managing out-break diseases $(0.26 \%$ of local expenditure and $7.37 \%$ from eliminating communicable diseases program in HDO) and some districts have a budget for emergency incidents $(0.32 \%$ of local expenditure and $7.71 \%$ from eliminating communicable diseases program in HDO). In fact, just some districts had allocated a budget for outbreak diseases due to disaster, particularly in 2012.

Conclusion: An inadequate budgets for disaster and health crisis by District Health Offices (DHO). Budgeting for disaster and health crisis still depends on the government's will to do so. It must be considered by local disaster and health crisis analysis; by local governments. Disaster experiences have not been a basis for planning and budgeting disaster programs yet.

Prehosp Disaster Med 2017;32(Suppl. 1):s63

doi:10.1017/S1049023X17001716

\section{Overview of the Project for Strengthening the ASEAN Regional Capacity on Disaster Health Management (ARCH Project) Yasushi Nakajima ${ }^{1}$, Phumin Silapunt ${ }^{2}$ \\ 1. Technical Advisor, System Science Consultants, Tokyo/Japan \\ 2. National Institute of Emergency Medicine, Nonthaburi/Thailand}

Study/Objective: Through the three-year period (July 2016 August 2019), the Project aims to strengthen regional coordination capacity on disaster health management in the Association of Southeast Asian Nations (ASEAN).

Background: In the ASEAN region, a total of 425,000 people were dead due to natural disasters from 1975 to 2015 [1], which disturbed economic growth and human security. The ASEAN has continued to attach the importance of cooperation related to the prevention of, and response to disasters. In addition, disaster health management was defined as one of the priority issues in the ASEAN Post-2015 Health Agenda. Through the preliminary survey and discussions, all ASEAN Member States (AMS) reached a common understanding on the importance of a regional collaboration mechanism in disaster health management. Based on that, the Project of Strengthening the ASEAN Regional Capacity on Disaster Health Management (the Project) was formulated. The Project was officially endorsed by Senior Officials Meeting on Health Development (SOMHD) of ASEAN in September 2015, and the Committee of Permanent Representatives (CPR) in January 2016.

Methods: To achieve the above objective, the following four activities will be conducted in cooperation between National Institute of Emergency Medicine (NIEM) of Thailand and Japan International Cooperation Agency (JICA) with involving all AMS: (1) Discussions on strengthening coordination capacity on disaster health management at the regional coordination meetings; (2) Cooperation and experience sharing through conducting regional collaboration drills; (3) Development of tools on effective regional collaboration on disaster health management; (4) Designing and conducting trainings on disaster health management.

Results: The Project has commenced in July 2016 and the first regional coordination meeting was held on September 29-30, 2016. In the meeting, all of the stakeholders shared the objective and methodology of the Project, and agreed to continue collaborating to share an idea on future regional coordination on disaster health management.

Conclusion: The start-up drill will be held in January 2017. Based on the lessons learned, recommendations and discussions 